\title{
Simultaneous Modelling of Gravity and Magnetic Data in a Measured Heat Flux Area to Characterize Geothermal Heat Sources: A Case for Eburru Geothermal Complex, Kenya
}

\author{
Erick Rayora Nyakundi*, Githiri J. Gitonga, Maurice O. K'Orowe \\ Department of Physics, Jomo Kenyatta University of Agriculture and Technology, Nairobi, Kenya \\ Email: *rayoraerick@yahoo.com
}

How to cite this paper: Nyakundi, E. R., Gitonga, G. J., \& K'Orowe, M. O. (2021). Simultaneous Modelling of Gravity and Magnetic Data in a Measured Heat Flux Area to Characterize Geothermal Heat Sources: A Case for Eburru Geothermal Complex, Kenya. Journal of Geoscience and Environment Protection, 9, 40-54.

https://doi.org/10.4236/gep.2021.95005

Received: December 4, 2020

Accepted: May 23, 2021

Published: May 26, 2021

Copyright $\odot 2021$ by author(s) and Scientific Research Publishing Inc. This work is licensed under the Creative Commons Attribution International License (CC BY 4.0).

http://creativecommons.org/licenses/by/4.0/

\section{(c) (i) Open Access}

\begin{abstract}
Forward modelling of gravity and magnetic data was done simultaneously to show the correlation between gravity and magnetic anomalies on a measured heat flux region. The results were used to characterize the heat source structures in Eburru area. Modelling was done using Oasis montaj geosoft software which is an iteration process where the gravity and magnetic anomalies were calculated and compared to the observed residual anomaly until there was a fit. The start model was constructed based on depths from Euler deconvolution and models constrained using stratigraphy data from the existing wells in the study area. Forward modelling of gravity and magnetic data revealed intrusions within the Earth's subsurface with depth to the top of the sources ranging from $739 \mathrm{~m}$ to $5811 \mathrm{~m}$. The density of the sources ranges between $3.0 \mathrm{~g} / \mathrm{cm}^{3}$ and $3.2 \mathrm{~g} / \mathrm{cm}^{3}$ while their magnetic susceptibility was zero. This implies that intrusions from the mantle with a magnetic susceptibility of zero have temperatures exceeding the curie temperature of rocks. The density of the intrusions modelled was higher than $2.67 \mathrm{~g} / \mathrm{cm}^{3}$, the average crustal density, hence it explains the observed positive gravity anomaly. The results also revealed that areas with high heat flux have shallow heat sources and if the heat sources are deep, then there must be a good heat transfer mechanism to the surface.
\end{abstract}

\section{Keywords}

Forward Modelling, Gravity Anomaly, Magnetic Anomaly, Heat Source, Heat Flux, Geothermal Gradient, Eburru 


\section{Introduction}

Eburru area is in Kenya's Rift Valley, approximately $123 \mathrm{~km}$ West of Nairobi city as shown in Figure 1. It is a volcanic complex South of Lake Elementeita. The presence of a lake indicates enough water sipping down to the hot masses through the fractures and faults for geothermal heat production. There is evidence of lava flow near Lake Elementeita to the North and to the South of the study area. This shows that there was a volcanic activity which erupted to the surface in the form of lava flow, hence the possibility of a near-surface heat source. There is a depression at Oldoinyo, Opuru to the South of the study area and near Lake Elementaita to the North. This depression could be the opening of volcanic activity where materials came out of the surface or could be a lopolith where the volume of magma reduced due to decreased pressure and the overlying rocks collapsed inwards. The study area has an elevated geothermal gradient as evidenced by high heat flux values showing a possible underlying geothermal heat source.

Geothermal energy is the natural heat from the Earth's interior in form of magma which can be used as a source of renewable energy (World Energy Council, 2013).

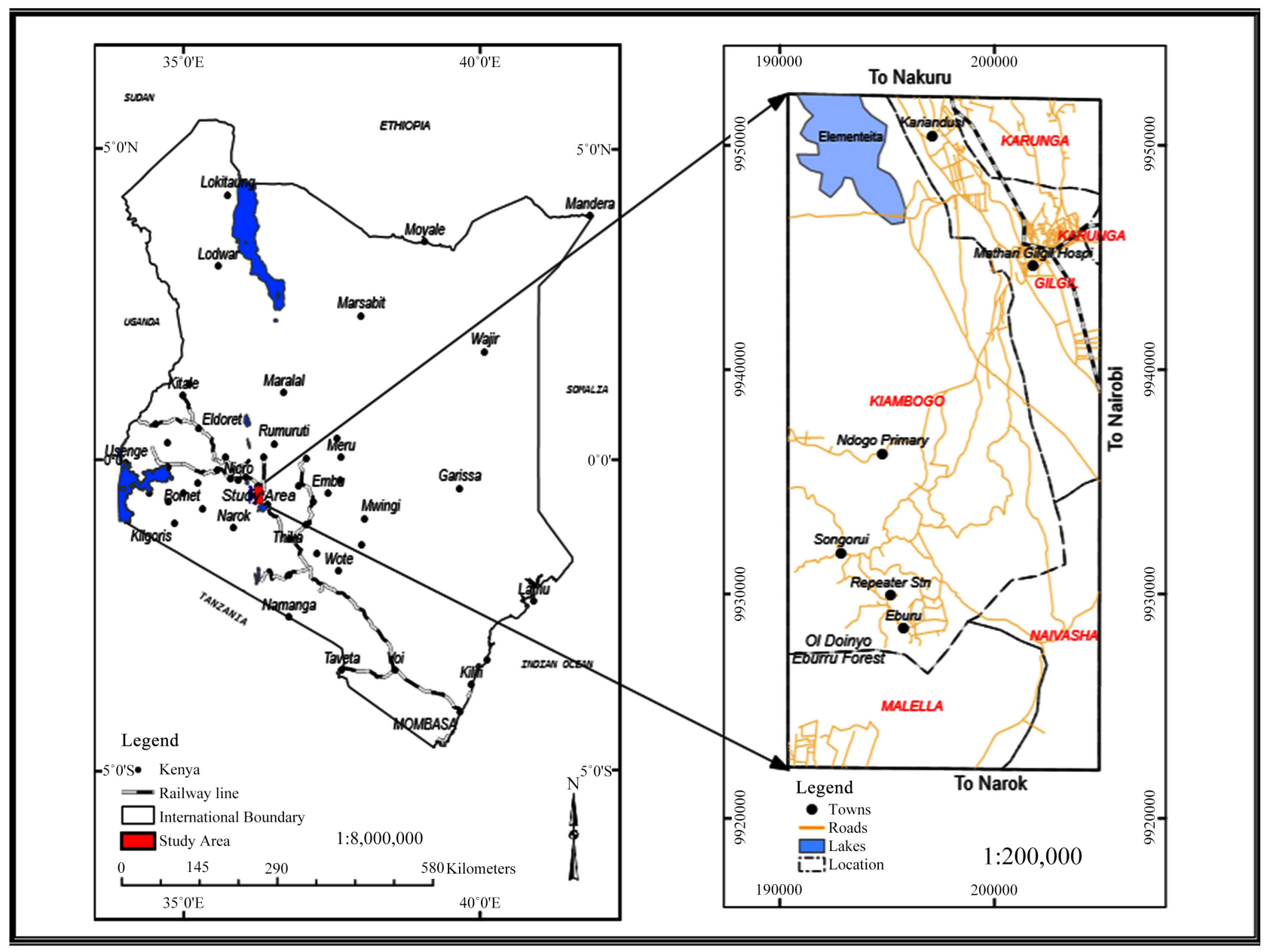

Figure 1. Map showing location of the study area. 
Magma is a hot molten material from the Earth's mantle. Because of the temperature gradient, there is a continuous heat flow from the Earth's interior which is hot towards the crust which is cooler. The Earth's crust is made up of tectonic plates with faults and fractures, which allow magma to penetrate to the Earth's surface in the form of lava flow. The large part of magma does not reach the surface and is trapped within the Earth's subsurface in the form of laccolith, batholith, dykes or sills. This forms geothermal heat sources. When meteorite water that seeps down through the faults and fractured rocks comes into contact with the hot magma and nearby heated hot rocks, it then gets heated and can come out to the surface as a hot spring or fumarole if in gaseous form. However, when this hot water flows under a layer of impermeable rock, it gets trapped underground and creates a geothermal reservoir with high steam pressure. The high steam pressure can be tapped to generate geothermal energy (Manzella, 2017).

The study area is characterized by faults which influence the flow of geothermal fluids within the Earth's subsurface. There are several fumaroles, dykes and volcanic craters an indication of various activities from the Earth's mantle towards the subsurface which is usually observed in geothermal energy areas. Geothermal grass that normally grows on a hot region is observed in this area which can be used to trace the hot graben within the subsurface. Also, there is presence of hot springs in the area indicating that there is a heat source underground where water gets heated and then flow out to the surface through the faults in form of hot springs. Therefore, this study conducted simultaneous modelling of gravity and magnetic data over a measured heat flux area to locate and characterize geothermal heat structures in the area. It included the location depth of the heat structures, their size and shape, density and magnetic susceptibility. The study was also taken to explain the correlation between heat flux, gravity and magnetic anomalies, density and magnetic susceptibility of the geothermal heat structures.

\subsection{Geology of the Study Area}

Eburru area has a volcanic geology with topographic rim of crater. The area has several points of eruption centers others with completely or almost completely buried by later pyroclastics. It is characterized by dykes, major faults and eruption fissures (Woodhall \& Clarke, 1988). Volcanic soil, lava flow, outcrop rocks, depression, trachyte, tuff, rhyolite, andesite, basalt and diatomite deposits are common in Eburru (Thompson \& Dodson, 1963). Figure 2 displays and summarizes the structural geology of Eburru study area case.

Eburru area has trachytes, pantellerites and pyroclastic rock types and it is associated with a basaltic field just to the North towards Elementaita basaltic area (Beltran \& Manuel, 2003). There is the presence of several faults and fissures which are essential at controlling recharge and fluid movement within a geothermal system. There is also the presence of altered grounds, hot grounds, active fumaroles area, geothermal grass cover, and hydrothermal deposits at the 


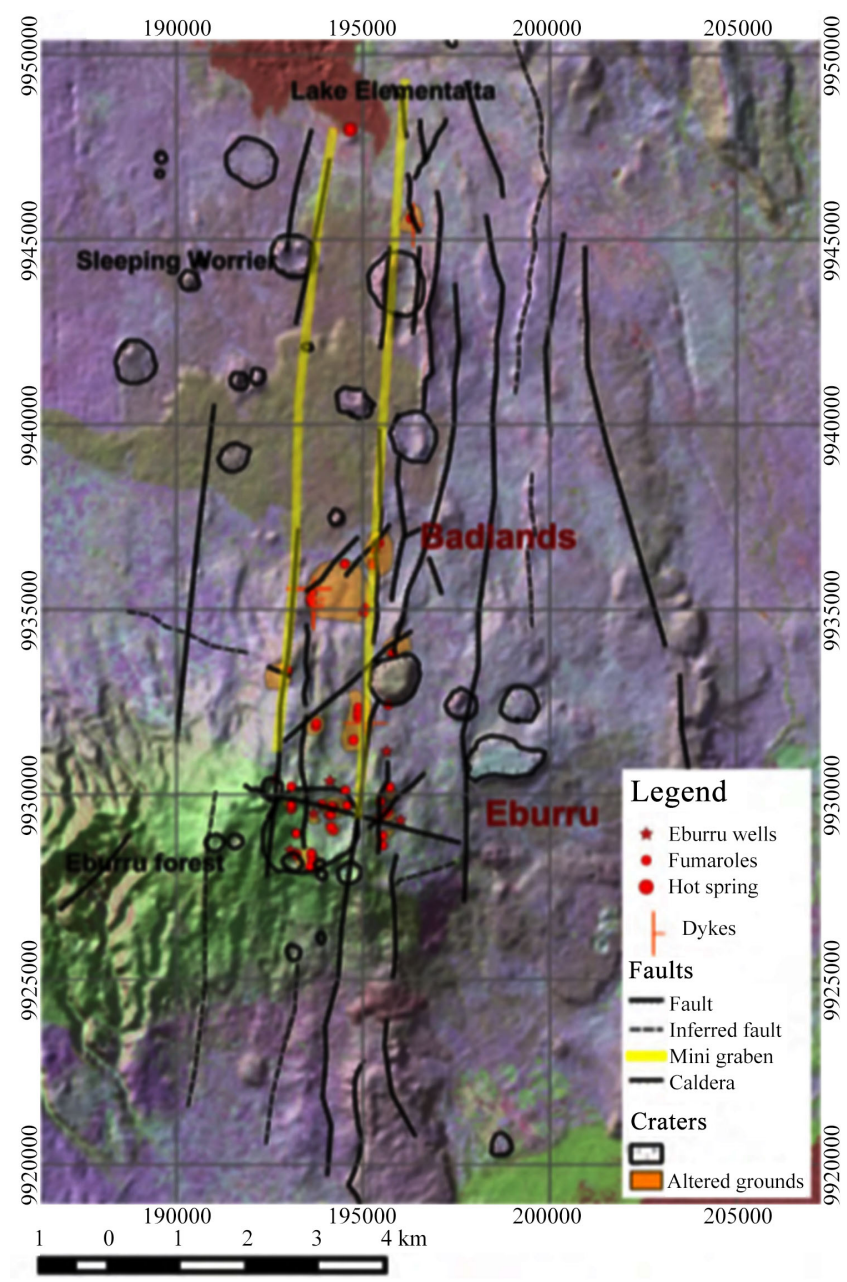

Figure 2. Map showing the structural geology of Eburru study area (Ronoh, 2015).

Eburru area. There is hydrogen sulphide smell at active fissures indicating the presence of intruding magma within the subsurface of the area (Kiende \& Kandie, 2015).

\subsection{Theory of forward Modelling}

Forward modelling of gravity and magnetic data entails determination of size, shape and physical parameters of the field anomaly source from the potential field measurements (Telford, Geldart, \& Sheriff, 1990). It entails an iteration process where the anomaly generated by the constructed computer model is compared with the measured residual anomaly (Abdelfettah et al., 2020). It is based on a starting model that is postulated from the geology of the study area (Aziz, Miller, Giraldo, \& Carigali, 2019). This is used to construct and constrain the computer models. The model parameters are varied and the anomaly calculation carried out. This is repeated until there is a fit between the calculated anomaly and the observed anomaly. However, this does not provide the only outcome as a number of models can result to the same anomaly (Kearey, Brooks, \& Hill, 2002). 


\subsection{Theory of forward Modelling of Gravity Data}

In a two-dimensional case, it is postulated that the causative body is infinitely long parallel to its cross-section surface. If line elements that are parallel to the strike are considered to replace the cross-sectional shape, then each line element contributes to the vertical component of gravity at the source as shown in Figure 3. By summing up the effect of all these line elements, the gravity anomaly of the causative body can be determined (Lowrie, 2007). This is an integration over the end surface of the causative body and the gravity anomaly is given by equation 1 . Therefore, forward modelling of gravity data determines the gravitational field produced by causative body underlying within the Earth's crust (Hirt, 2015).

$$
\Delta g_{z}=2 G \Delta \rho \oint z \mathrm{~d} \theta
$$

$\theta$ is the angle between $\mathrm{x}$-axis and the line from the origin to the gravity anomaly source, $g_{z}$ is the vertical gravitational field, $G$ is the universal gravitational constant and $z$ is the depth to the source as shown in Figure 3. The integration over the end-surface is converted to an integration around its boundary. The computer algorithm for the calculation of this integral is done by replacing the original cross-sectional shape with an $\mathrm{n}$-sided polygon as shown in Figure 3. The polygon corners position $(x, z)$ and density contrast are used to compute the gravity anomaly. If the source is shifted to the next position along the profile, the $\mathrm{x}$-coordinate of the polygon corners vary. This is repeated until the computed anomaly of the gravity model fits with the measured residual anomaly.

\subsection{Theory of forward Modelling of Magnetic Data}

Forward modelling of magnetic data involves construction of an initial model based on the geology of the study area and its anomalies calculated. The calculated magnetic anomaly is compared to the observed anomaly. This is repeated until the computed and observed anomaly fit. In two-dimensional magnetic modelling, the cross-sectional shape of the causative mass is assumed to be of a polygon (Kearey et al., 2002). The magnetic anomaly of the polygon is determined by summing up of the individual contributions of infinite slabs with sloping edges corresponding to the sides of the polygon as displayed in Figure 4. The horizontal magnetic field $\Delta H$, vertical magnetic field $\Delta Z$ and total magnetic field $\Delta B$ anomalies in nanotesla of the slab displayed in Figure 4 are given by Equations (2)-(4) respectively (Kearey et al., 2002).

$$
\begin{array}{r}
\Delta Z=200 \sin \theta\left[J_{x}\left\{\sin \theta \log \left(\frac{r_{2}}{r_{1}}\right)+\varphi \cos \theta\right\}+J_{z}\left\{\cos \theta \log \left(\frac{r_{2}}{r_{1}}\right)-\varphi \sin \theta\right\}\right] \\
\Delta H=200 \sin \theta\left[J_{x}\left\{\varphi \sin \theta-\cos \theta \log \left(\frac{r_{2}}{r_{1}}\right)\right\}+J_{z}\left\{\varphi \cos \theta+\sin \theta \log \left(\frac{r_{2}}{r_{1}}\right)\right\}\right] \sin \alpha \\
\Delta B=\Delta Z \sin I+\Delta H \cos I
\end{array}
$$

where the angles are given in radians. 


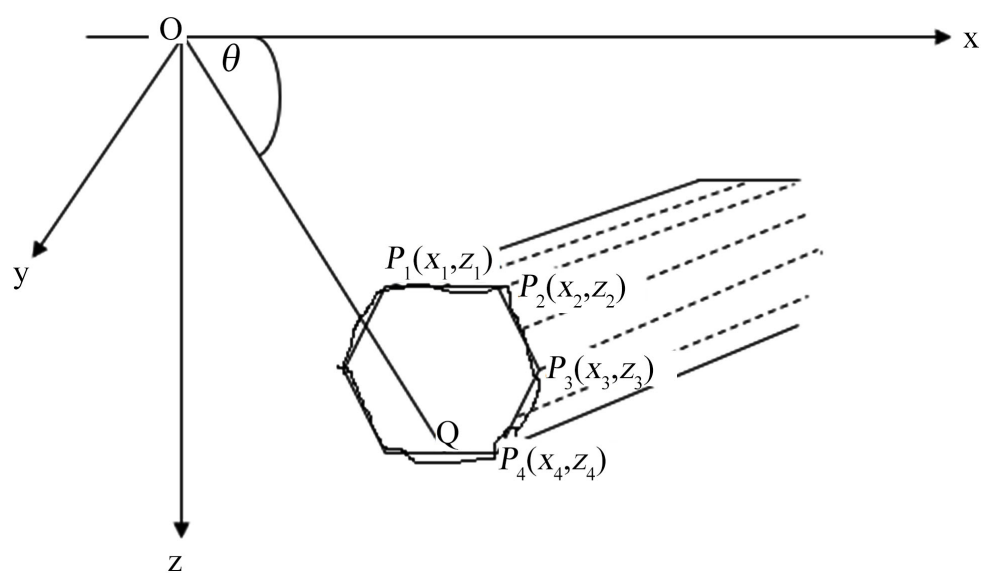

Figure 3. Determination of gravity anomaly of irregular body using multi-sided polygon.

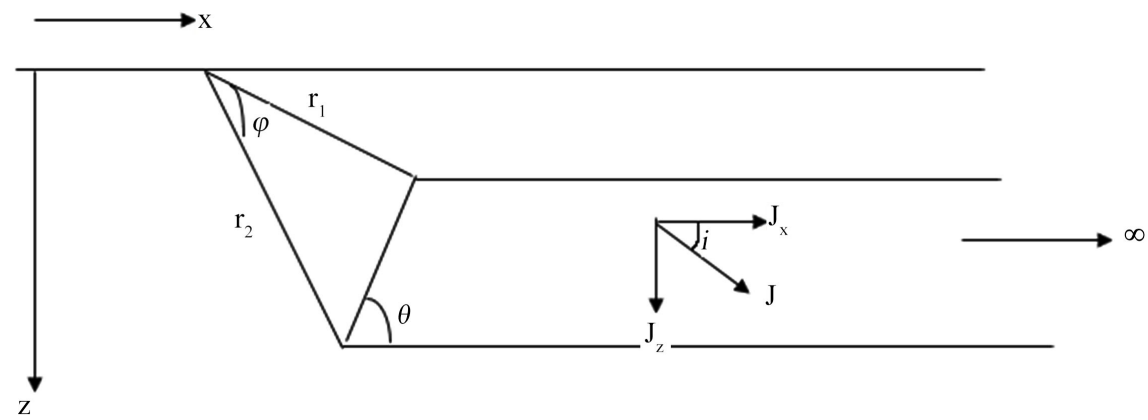

Figure 4. Quantities applied in describing magnetic anomaly of a slab with a sloping edge.

$J_{x}=J \cos i$ and $J_{z}=J \sin i$ are the horizontal and vertical components of the magnetization $J$, $a$ is the horizontal angle between the direction of the profile and magnetic north. $i$ is the inclination of the geomagnetic field.

\section{Methodology}

Forward modelling of gravity and magnetic data was done simultaneously using $\mathrm{Gm}$-sys in oasis montaj geosoft software. It entailed an iteration process where the anomaly generated by the constructed computer model was compared with the observed residual anomaly (Abdelfettah et al., 2020). The starting model was postulated from Euler deconvolution depths and models constrained based on the structural geology and stratigraphy data from existing wells within the study area. The geology of Eburru study area is of volcanic origin dominated by basalt, andesite, granite, rhyolite, trachyte, tuff, ignimbrites and pyroclastic flow (Kiende \& Kandie, 2015). This was used to construct and constrain the density and magnetic susceptibility of computer models. The model parameters were varied and calculations performed. This was repeated until there was a match between the calculated anomaly and the observed anomaly. The selected profiles for forward modelling were chosen on the basis of heat flux information displayed in Figure 5. Figure 6 and Figure 7 show the location of the profiles on gravity and magnetic maps respectively. 


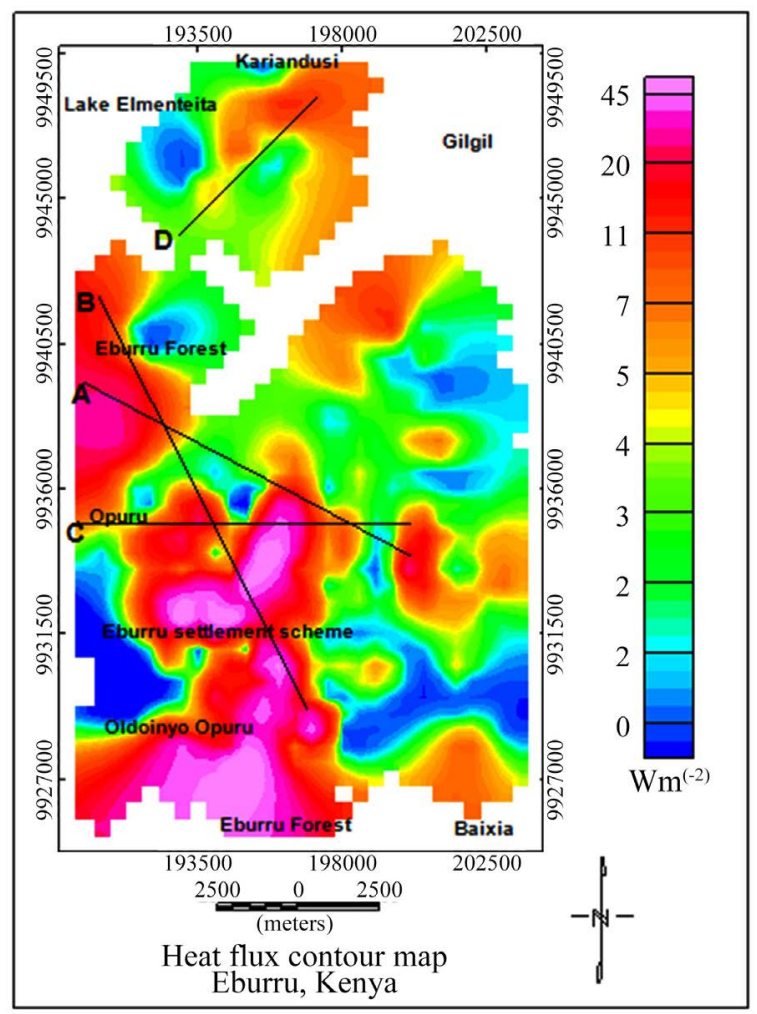

Figure 5. Heat flux map showing selected profiles for forward modelling.

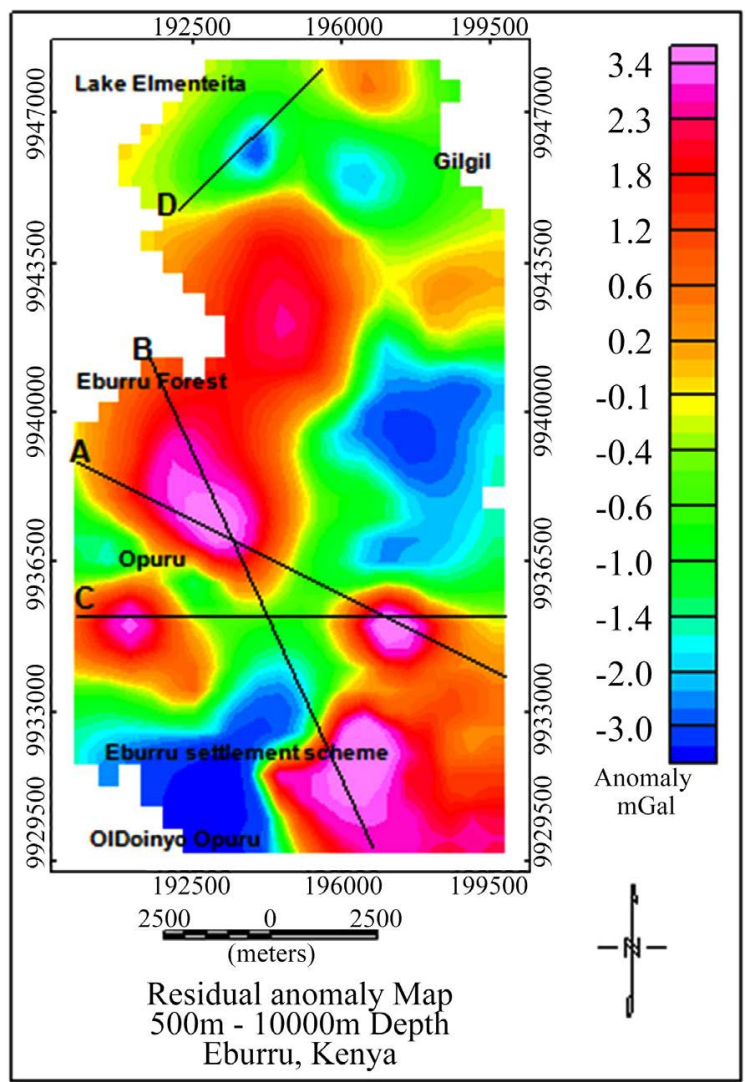

Figure 6. Location of modelling profiles on a gravity anomaly map. 


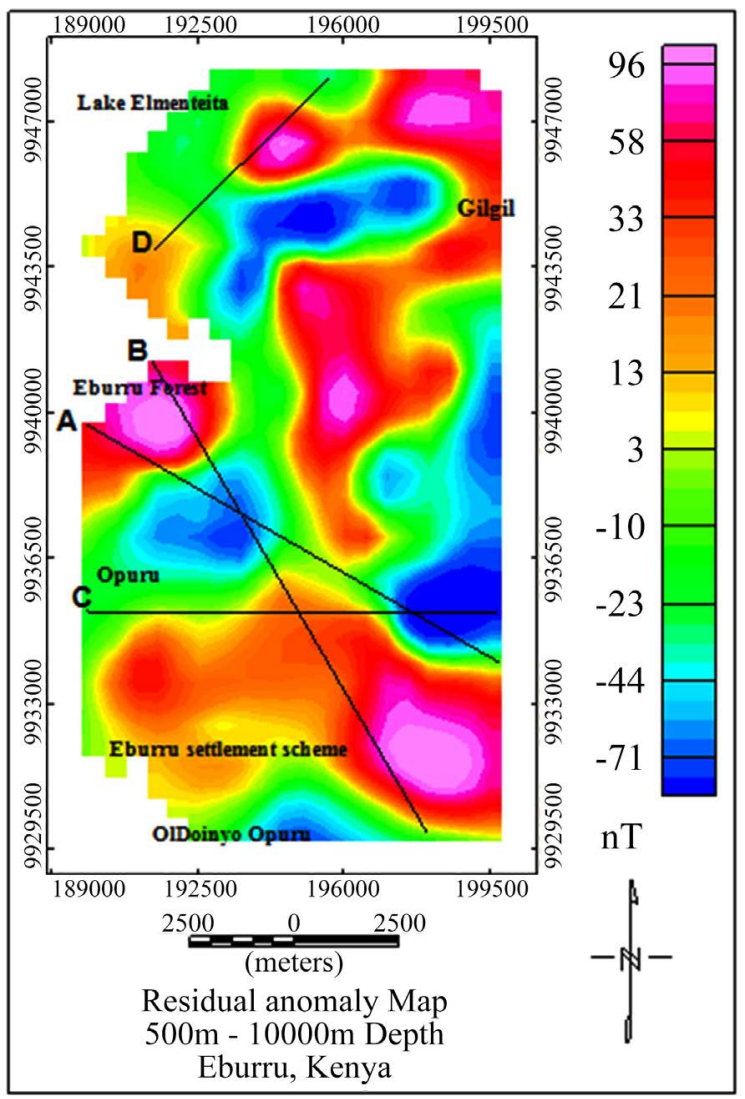

Figure 7. Location of modelling profiles on a magnetic anomaly map.

Figure 5 shows selected profiles on a heat flux map used for forward modelling of gravity and magnetic data. The profiles were selected on the basis of heat flux values within the study area. They were cutting high and low heat flux areas. High heat flux indicates an elevated geothermal gradient because of a possible near-surface heat source, a good heat transfer mechanism to the surface or presence of radioactive elements (Georgsson, 2013). Low heat flux may be due to absence of a near-surface heat source or poor heat transfer mechanism to the surface (Mwawongo, 2013). Forward modelling of gravity and magnetic data was done simultaneously along these profiles for correlation and to image the possible causes in the Earth's crust of the observed heat flux values.

\section{Results}

Figures 8-11 display the outcome of the computed gravity and magnetic anomaly and its comparison with the observed residual anomaly. They also display the determined depth, density, and magnetic susceptibility of causative bodies.

Figure 8 shows model A which is at the Central part of the study area. Model A was constructed from profile A as shown from gravity and magnetic anomaly maps in Figure 6 and Figure 7 respectively. The profile trend is from Northwest to Southeast direction in the study area. It cuts across a high heat flux region at the middle and a low heat flux region to the Southeast part of the profile as 
shown from a heat flux map in Figure 5. Gravity and magnetic data as shown in Figure 6 and Figure 7 were modelled simultaneously to compare their outcome and reveal the possible underlying causative sources. The model was constrained using stratigraphy data from existing wells and the geology of the study area. The model reveals a mafic intrusion at a distance of $6466 \mathrm{~m}-7009 \mathrm{~m}$ along the profile which was interpreted to be of basaltic rock origin at a depth range of $2248 \mathrm{~m}-2290 \mathrm{~m}$. There is a second intrusion at a distance of $474 \mathrm{~m}-3302 \mathrm{~m}$

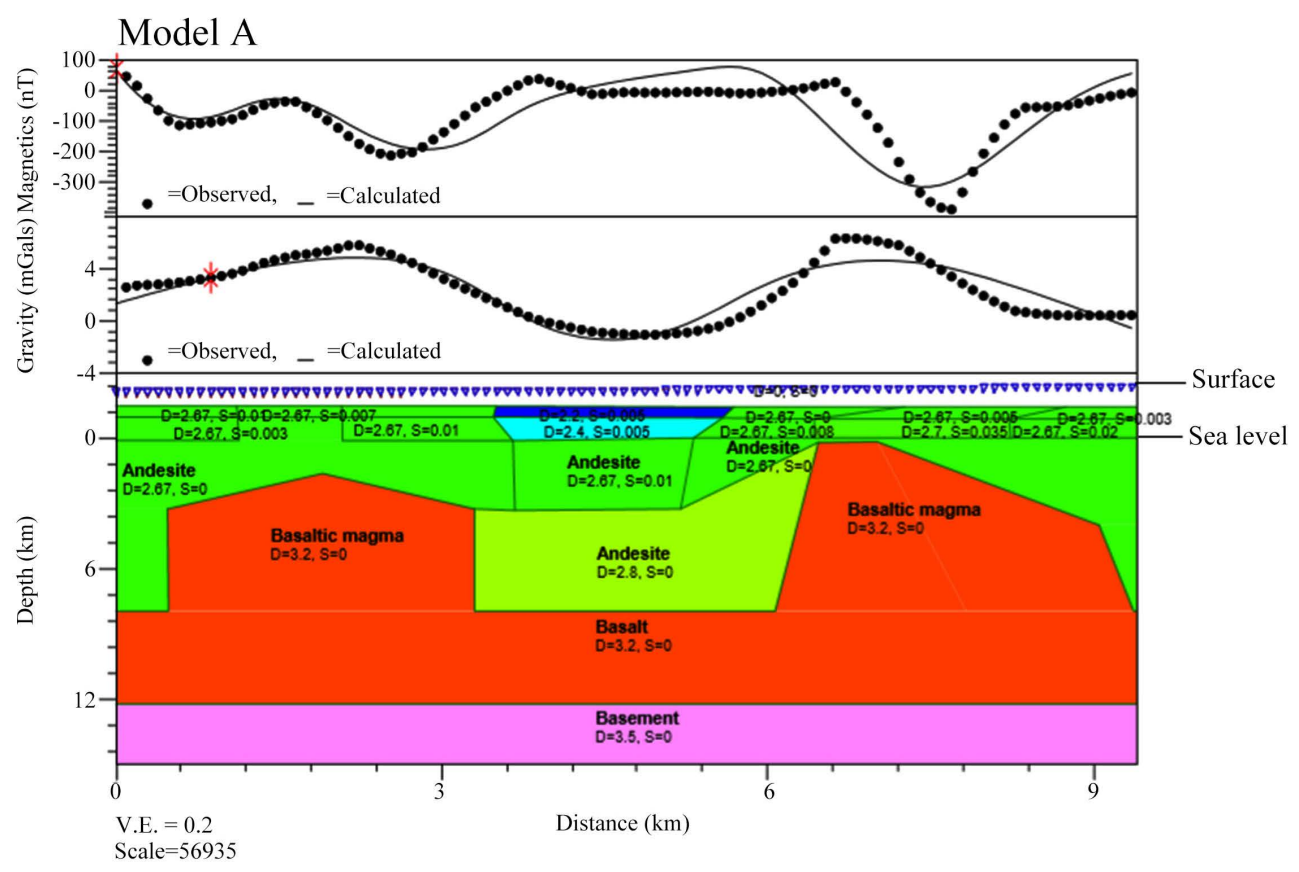

Figure 8. Model A constructed from profile A.

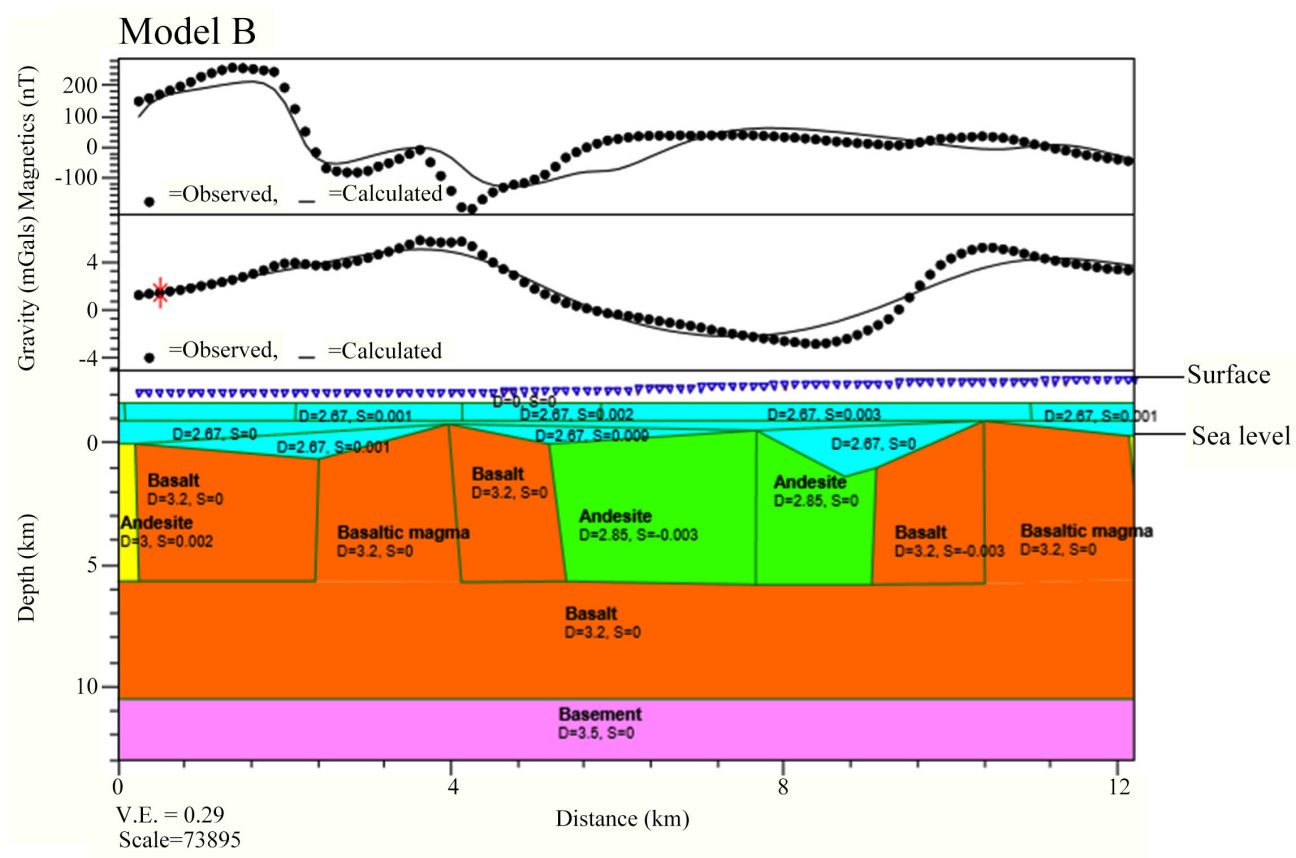

Figure 9. Model B constructed from profile B. 


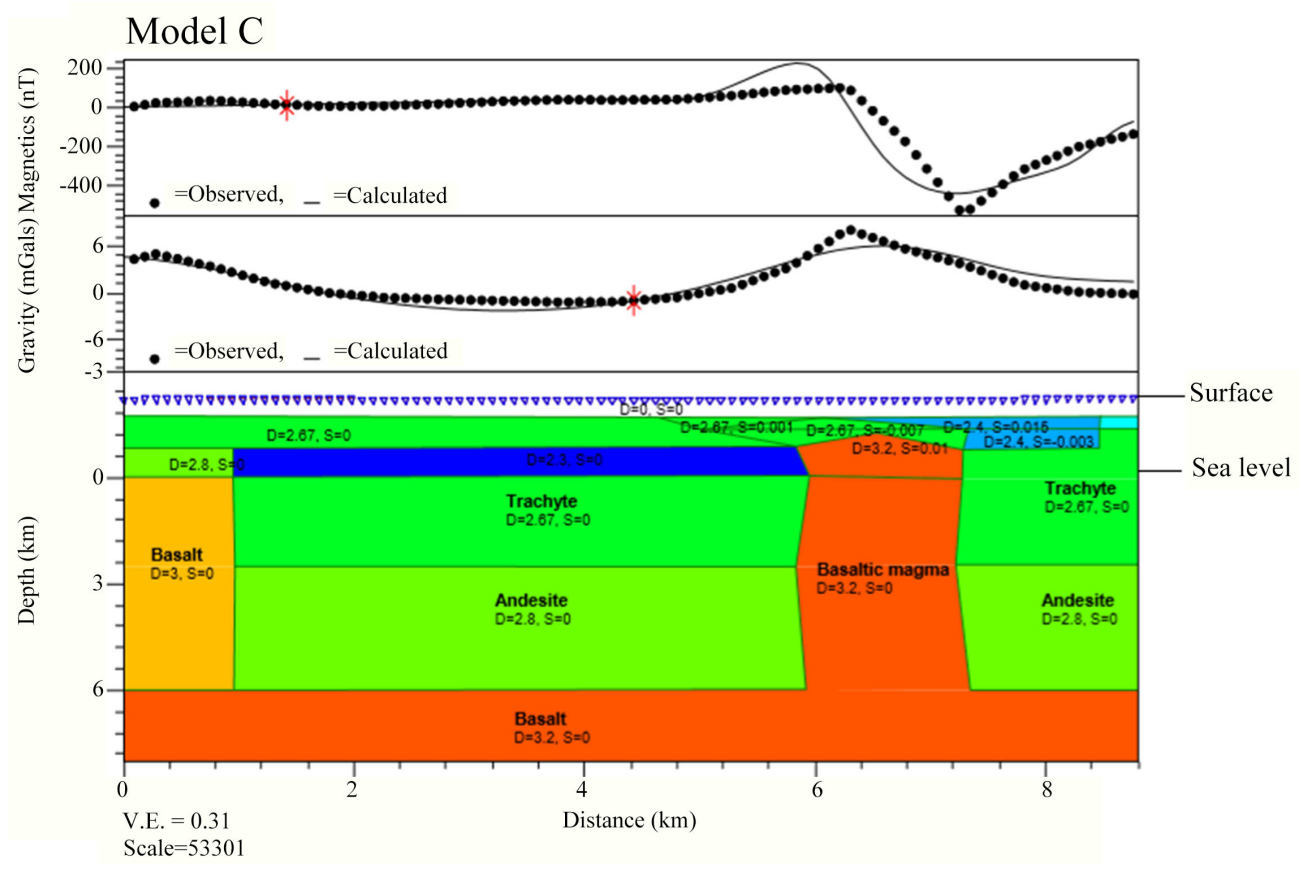

Figure 10. Model C constructed from profile C.

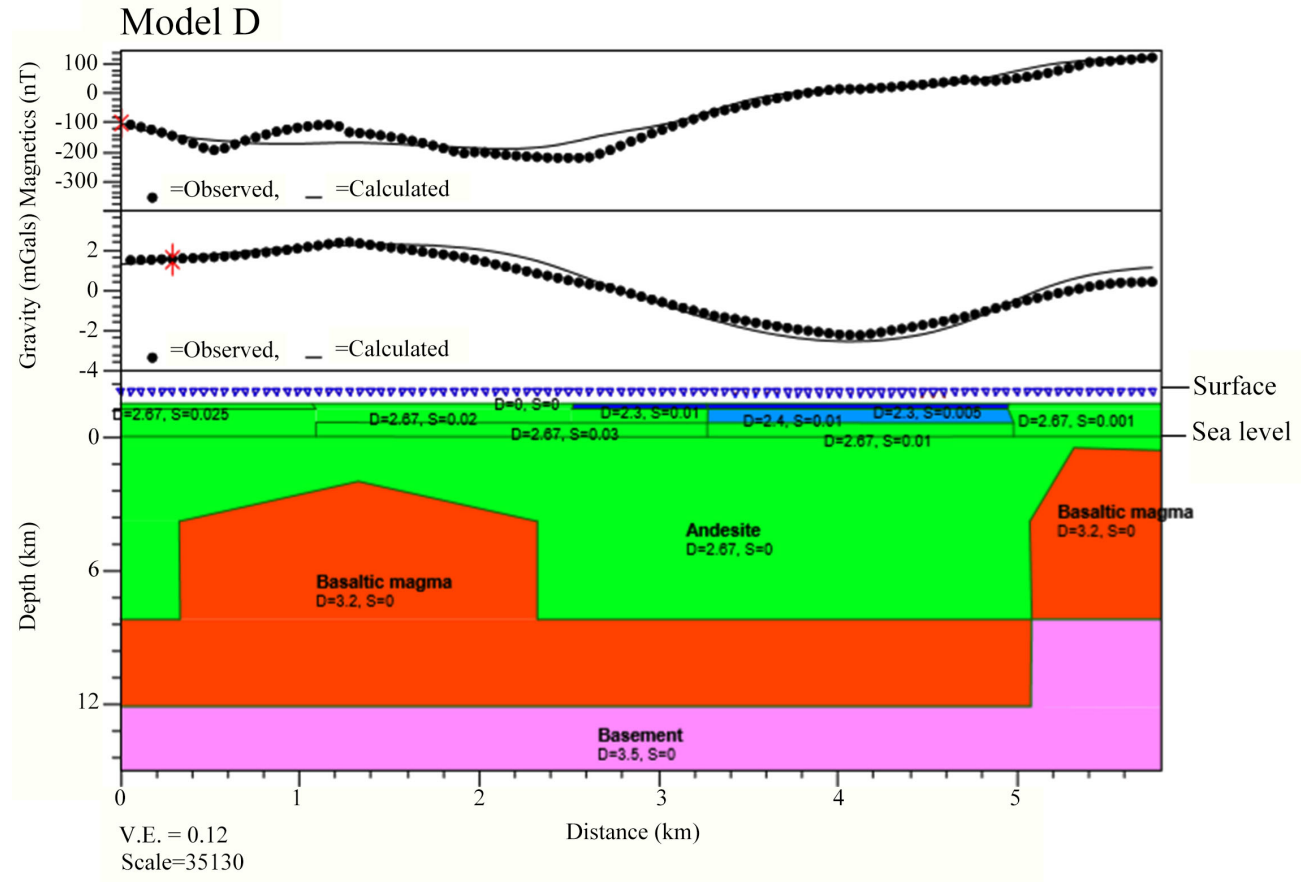

Figure 11. Model D constructed from profile D.

along the profile occurring at a depth range of $3556 \mathrm{~m}$ - $5187 \mathrm{~m}$ deep with a peak intrusion of $3556 \mathrm{~m}$ deep occurring at $1905 \mathrm{~m}$ along the profile. These intrusions are covered by a layer of less dense andesitic origin rock at a depth of $2145 \mathrm{~m}$. There are anomaly sources at the top interpreted to be of trachyte, rhyolite, tuff, ignimbrites, and pyroclastic volcanic rocks origin as displayed in Figure 8. The intrusions have a density of $3.2 \mathrm{~g} / \mathrm{cm}^{3}$ and magnetic susceptibility of 0 . Magnetic 
susceptibility of zero implies high temperature at this depth that is capable of destroying magnetism of the host rock completely (Telford et al., 1990). Considering magnetite which is the most abundant magnetic rock within the Earth's crust, temperature at this depth could be greater than $578^{\circ} \mathrm{C}$ (Reynolds, 1998). The intrusions are interpreted to be of rhyolite origin where the upwelling magma released heat to the crustal rocks resulting to their melting. This generates new crustal magma that is possibly rich in silica and low iron content resulting to zero magnetic susceptibility. The volcanic deposits to near surface are showing magnetic susceptibility ranging from $0.008 \mathrm{cgs}-0.03 \mathrm{cgs}$ implying temperatures are lower than the curie point temperature. The variation of density and magnetic susceptibility images the Earth's subsurface faults and fractures that influence the movement of geothermal fluids. These intrusions were interpreted to be originating possibly from a basement batholith and then intrude up in the form of dykes.

Figure 9 shows model B which was constructed from profile B displayed in gravity and magnetic anomaly maps in Figure 6 and Figure 7 respectively. Profile B runs from Northwest to Southeast direction of the study area cutting through Eburru settlement scheme to the Eburru forest. The geothermal gradient increases from low at Northwest part of the profile and becomes very high to the Southeast part along profile B as shown from heat flux map in Figure 5. Model B reveals basaltic magmatic intrusion as shown in Figure 9. The first intrusion occurs at a distance range of $207 \mathrm{~m}-2412 \mathrm{~m}$ along the profile with the depth to the top of the intrusion ranging between $2527 \mathrm{~m}-3160 \mathrm{~m}$. The second intrusion occurs at a distance of $2412 \mathrm{~m}-3970 \mathrm{~m}$ along the profile with the depth to the top ranging between $1714 \mathrm{~m}-3160 \mathrm{~m}$ as shown in Figure 9. The intrusion appears to be caused by rising of hot magma from the mantle resulting to basaltic magma rich in garnetiferous and peridotitic minerals. The third intrusion is imaged at a distance of $3970 \mathrm{~m}-5177 \mathrm{~m}$ along the profile with depth to top of the source ranging between $1714 \mathrm{~m}-2543 \mathrm{~m}$ as displayed in Figure 9. The fourth intrusion occurs at $9105 \mathrm{~m}-10,400 \mathrm{~m}$ along profile B having a depth to top of the source ranging between $1596 \mathrm{~m}-3521 \mathrm{~m}$. The fifth intrusion occurs at a distance of $10,400 \mathrm{~m}-12,144 \mathrm{~m}$ along the profile with the depth to the top of sources ranging between $1595 \mathrm{~m}-2211 \mathrm{~m}$. The model in Figure 9 images shallow magma sources, an indication of rhyolite magma due to basaltic andesite magma releasing heat to the crustal rocks causing their melting. This causes a reduction in magnetic susceptibility. The density of the sources was modelled to be $3.2 \mathrm{~g} / \mathrm{cm}^{3}$ which is higher than $2.67 \mathrm{~g} / \mathrm{cm}^{3}$, the average density of the crustal rocks (Hinze, 2003) explaining the observed gravity high. This shows that possibly the masses causing the gravity anomaly came from the mantle resulting to basaltic magma. The magnetic susceptibility of the intrusions was modelled to be zero. This implies the intrusions have higher temperatures that cannot support magnetism of rocks. The model shows the basaltic sources intruding between the andesitic rocks. The top layer was modelled to be a trachyte rock of density 2.67 $\mathrm{g} / \mathrm{cm}^{3}$ overlying the basalt intrusions and andesite. Trachyte is covered with a se- 
ries of rhyolite, tuff and pyroclastic volcanic materials with a density of 2.67 $\mathrm{g} / \mathrm{cm}^{3}$. The volcanic rocks at the top show magnetic susceptibility ranging between $0.001-0.009$ c.g.s units suggesting temperatures have dropped to the level of supporting magnetism.

Figure 10 shows model $\mathrm{C}$ which was constructed from profile $\mathrm{C}$ as shown from gravity and magnetic anomaly maps in Figure 6 and Figure 7 respectively. The profile cuts across a high heat flux region through Opuru in the East-West direction of the study area as displayed from heat flux map in Figure 5. There is a low heat flux region to the West, high heat flux region at the middle, and finally a low heat flux region to the East along profile C. The model was constrained using stratigraphy data from the existing wells and geology of the study area. Model C in Figure 10 reveals a quiet zone within the subsurface with few intrusions' sources. The first intrusion occurs at a distance of $0 \mathrm{~m}-951 \mathrm{~m}$ along profile $\mathrm{C}$ having a depth of $1984 \mathrm{~m}$ to the top of the anomaly source. This source occurs at a relatively low heat flux region. The second intrusion occurs at a distance of $5834 \mathrm{~m}-7284 \mathrm{~m}$ along the profile with a depth range of $739 \mathrm{~m}-1211 \mathrm{~m}$ to the top of the anomaly source. The peak is imaged at a distance of $6531 \mathrm{~m}$ along the profile with a depth of $739 \mathrm{~m}$ to the top of the intrusion source. The density of the intrusions ranges between $3.0 \mathrm{~g} / \mathrm{cm}^{3}$ and $3.2 \mathrm{~g} / \mathrm{cm}^{3}$ indicating a gravity high. This implies the anomaly source emanated from upwelling of magma materials from the mantle, thus resulting into a denser basaltic intrusion than crustal rocks. The magnetic susceptibility of the intrusions was modelled to be zero, indicating higher temperatures than the curie temperature. There is a series of rhyolite, tuff, pyroclastic and ignimbrites volcanic deposits at depth range of $0 \mathrm{~m}-1211 \mathrm{~m}$. The magnetic susceptibility ranges between $-0.005 \mathrm{cgs}$ and 0.015 cgs indicating low temperatures that can support magnetism of rocks.

Figure 11 shows model D which was plotted along profile D to the Northern part of the study area near Lake Elementaita as displayed from gravity and magnetic anomaly maps in Figure 6 and Figure 7 respectively. It runs from the Southwest to the Northeast of the study area and cuts along a high heat flux region as shown from a heat flux map in Figure 5. Model D was done to image the possible causes of high heat flux values and presence of lava flows along profile D. The model was constrained using stratigraphy data from the existing wells and the geology of the study area. Model D reveals two mafic intrusions within volcanic rocks as in Figure 11. The first intrusion occurs at a distance of $328 \mathrm{~m}$ to $2324 \mathrm{~m}$ along the profile and the depth to the top of the anomaly source ranges between $4000 \mathrm{~m}$ to $5801 \mathrm{~m}$. The peak of the anomaly source is imaged at $1326 \mathrm{~m}$ along the profile with a depth of $4000 \mathrm{~m}$. This is a deep source and was interpreted to be a rhyolite magma lying on top of a basaltic magma. This is because probably the melting temperature of rocks was lowered by the sipping down of water from lake Elementaita. The hot underlying basaltic magma transfers heat to the rocks causing them to melt. The melt rises up, transferring heat energy to the top rocks causing their melting. This results into a rhyolite magma because of the crust melting. The second intrusion occurs at a distance range of 
$5067 \mathrm{~m}$ to $5830 \mathrm{~m}$ along the profile as shown in Figure 11. The depth to the top of the anomaly source ranges between $2486 \mathrm{~m}$ to $5811 \mathrm{~m}$. The peak is imaged at a distance of $5314 \mathrm{~m}$ along the profile with a depth of $2486 \mathrm{~m}$ to the top of the anomaly source. This was interpreted to be a mafic intrusion in the form of a basaltic magma from the mantle. Model D in Figure 11 shows the top layers with andesite, trachyte, rhyolite, ignimbrites and tuff volcanic rocks. This implies there was a volcanic activity in the area, hence explains the presence of lava flows in the area. The density of the two modelled intrusions is $3.2 \mathrm{~g} / \mathrm{cm}^{3}$ which is a gravity high. Gravity high is an indication of denser materials than the host rocks. This is because gravity is a function of density and as density of underlying rocks increases, the gravity value also increases (Lowrie, 2007). The magnetic susceptibility of the two modelled intrusions is zero, implying higher temperature than the curie temperature of rocks. The magnetic susceptibility of top layers ranges between $0.001-0.03$ cgs units indicating lower temperatures than curie temperature.

\section{Conclusion}

Forward modelling of gravity and magnetic data for the profiles displayed in Figures 5-7 reveals intrusions in the Earth's crust. The depth to the top of the intrusions range from the shallowest at $739 \mathrm{~m}$ to the deepest at $5811 \mathrm{~m}$. Model C which cuts across a high heat flux region in Opuru area images the shallowest intrusion at a depth of $739 \mathrm{~m}$ while model D which is relatively on a low heat flux region near Lake Elmenteita to the North of the study area images the deepest intrusion at a depth of $5811 \mathrm{~m}$. This study reveals that regions with high heat flux have shallow heat sources while regions with low or moderate heat flux have deep heat sources. These intrusions were interpreted possibly to be magmatic heat sources.

The densities of the anomaly sources range between $3.0 \mathrm{~g} / \mathrm{cm}^{3}$ and $3.2 \mathrm{~g} / \mathrm{cm}^{3}$ implying the intrusions are from the mantle materials or dykes extending from a batholith rock. This indicates that intrusions from the mantle have higher density than the average density of crustal rocks. This verifies the fact that density of rocks in the Earth increases with depth. These intrusions were interpreted to be a basaltic magma. The magnetic susceptibility of the intrusions was modelled to be 0 , implying higher temperatures than the curie temperature of the crustal rocks. This implies that intrusions from the mantle have higher temperatures than the curie temperature of crustal rocks. This could be geothermal heat sources. The study reveals that a causative body with positive gravity anomaly and zero magnetic susceptibility could be a geothermal heat source.

Forward modelling of gravity and magnetic data simultaneously shows that geothermal heat source has positive gravity anomaly and 0 magnetic susceptibility. Positive gravity anomaly verifies the fact that the density of rocks in the Earth increases with depth, explaining the higher density of materials intruding from the mantle than the density of crustal rocks. Magnetic susceptibility of 0 indicates that these bodies have higher temperature that destroys magnetism of 
constituent rocks, hence could be hot geothermal heat sources. Considering magnetite which is the most abundant magnetic rock in the Earth, the temperature of the anomaly source could be greater than its curie temperature of $578^{\circ} \mathrm{C}$.

Spectral analysis of ground magnetic data in this study area was done and revealed a geothermal isotherm depth of $2150 \mathrm{~m}$ (Nyakundi, Githiri, K'Orowe, \& Ombati, 2019) which is within the depth range determined by this forward modelling of gravity and magnetic data. This implies that at the geothermal isotherm depth of $2150 \mathrm{~m}$, the temperature is greater than the curie temperature of crustal rocks. This means that the geothermal gradient reduces with depth considering the heat flux values at the Earth's surface. This is an indication that the heat from the source is trapped at a particular depth within the Earth's subsurface and does not flow freely to the surface. When the heat source is approached, the temperature is high and becomes nearly constant. This could be possibly caused by the presence of a permeable rock between the heat source beneath and the impermeable rock on top that lowers the rate of heat transfer to the surface. This result shows that spectral analysis of magnetic data can be used to determine the depth and estimate temperature of a geothermal heat source. The temperature becomes greater than the curie temperature of crustal rocks while the depth is the curie isotherm depth. From this study, areas with high heat flux values on top of the intrusions should be sited for geothermal wells as they indicate a shallow heat source with a reduced geothermal gradient with depth. Reducing geothermal gradient implies the presence of a high temperature heat source where temperature increases rapidly from the Earth's surface and becomes nearly constant when its depth is approached.

\section{Acknowledgements}

Thanks to the Kenya Electricity Generating Company KenGen for gravity and magnetic data.

\section{Conflicts of Interest}

The authors declare no conflicts of interest regarding the publication of this paper.

\section{References}

Abdelfettah, Y., Hinderer, J., Calvo, M., Dalmais, E., Maurer, V., \& Genter, A. (2020). Using Highly Accurate Land Gravity and 3D Geologic Modeling to Discriminate Potential Geothermal Areas: Application to the Upper Rhine Graben, France. Geophysics, 85, 35-56. https://doi.org/10.1190/geo2019-0042.1

Aziz, F., Miller, R., Giraldo, C., \& Carigali, P. (2019). Improving Deep Crustal Structure Depth Interpretation by Integrating 2D Gravity-Magnetic Modelling and Structural Restoration: Offshore Borneo. Paper presented at the SEG International Exposition and 89th Annual Meeting, San Antonio, 17 September 2019, 1719-1723. https://doi.org/10.1190/segam2019-3215966.1

Beltran, V., \& Manuel, J. (2003). The Origin of Pantellerites and the Geology of the Eburru 
Volcanic Complex, Kenya Rift, Africa. ETD Collection for University of Texas, El Paso.

Georgsson, L. (2013). Geophysical Methods Used in Geothermal Exploration. Short Course VIII on Exploration for Geothermal Resources, Organized by UNU-GTP, GDC and KenGen, Lake Bogoria and Lake Naivasha, Kenya.

Hinze, W. J. (2003). Bouguer Reduction Density, Why 2.67? Geophysics, 68, 1559-1560. https://doi.org/10.1190/1.1620629

Hirt, C. (2015). Gravity Forward Modelling. In E. Grafarend (Ed.), Encyclopedia of Geodesy. Cham: Springer. https://doi.org/10.1007/978-3-319-02370-0 106-1

Kearey, P., Brooks, M., \& Hill, I. (2002). An Introduction to Geophysical Exploration. Ames, IA: Iowa State University Press.

Kiende, R., \& Kandie, R. (2015). Structural Geology of Eburru Volcano and Badlands Geothermal Prospects in Kenya. Paper presented at the Fortieth Workshop on Geothermal Reservoir Engineering, Stanford University, Stanford, CA, 26-28 January 2015, 1-10.

Lowrie, W. (2007). Fundamentals of Geophysics (2nd ed.). New York: Cambridge University Press.

Manzella, A. (2017). Geothermal Energy. EPJ Web of Conferences, 148, Article ID: 00012. https://doi.org/10.1051/epjconf/201714800012

Mwawongo, G. (2013). Geothermal Mapping Using Temperature Measurements. Presented at Short Course VIII on Exploration for Geothermal Resources, Kenya, 31 October-22 November 2013, 1-13.

Nyakundi, E. R., Githiri, J., K’Orowe, M., \& Ombati, D. (2019). Spectral Analysis of Ground Magnetic Data Using Fast Fourier Transform In Eburru, Southern Rift, Kenya. IOSR Journal of Applied Geology and Geophysics, 7, 60-66.

Reynolds, J. M. (1998). An Introduction to Applied and Environmental Geophysics. Chichester, England: John Wiley \& sons Ltd.

Ronoh, I. (2015). Evolution and Geology of Eburru-Badlands Geothermal Prospect: Central Kenyan Rift. GRC Transactions, 39, 247-254.

Telford, W. M., Geldart, L. P., \& Sheriff, R. E. (1990). Applied Geophysics. Cambridge: Cambridge University Press. https://doi.org/10.1017/CBO9781139167932

Thompson, A., \& Dodson, R. (1963). Geology of the Naivasha Area. Report No. 55. Geological Survey of Kenya.

Woodhall, D. G., \& Clarke, M. C. G. (1988). Geological Map of Longonot Volcano, the Greater Olkaria and Eburru Volcanic Complexes and Adjacent Areas. England: Cook Hammond \& Kell Ltd.

World Energy Council (2013). World Energy Resources (pp. 354-415). London: World Energy Council. 